\title{
NILAI-NILAI PENDIDIKAN DALAM SENI KALIGRAFI KARYA MAHASISWA JURUSAN PENDIDIKAN GURU MADRASAH IBTIDAIYAH IAIN PONORGO
}

\author{
Tirta Dimas Wahyu Negara \\ Institut Agama Islam Negeri Ponorogo \\ tirta@iainponorogo.ac.id \\ Ratna Yunita \\ Institut Agama Islam Negeri Ponorogo \\ ratnayunita@iainponorogo.ac.id
}

\begin{abstract}
Abstrak
Setiap karya seni pada umumnya memiliki nilai khusus yang terkandung disetiap ide penciptaannya, bisa berupa nilai keindahan, nilai pendidikan, teknik pembuatan dan lain sebagainya. Kaligrafi islam merupakan salah satu media da'wah yang memiliki nilai pendidikan. Oleh karena itu artikel ini ingin mengulas hasil karya kaligrafi mahasiswa Jurusan Pendidikan Guru Madrasah Ibtidaiyah Institut Agama Islam Negeri Ponorogo dalam mata kuliah Pembelajaran Seni dan Budaya di Madrasah Ibtidaiyah. Penulisan ini adalah kualitatif yang bersifat deskriptif. Penulis mengolah data dimulai dengan studi pustaka, merumuskan tema, membuat kata kunci dan merumuskan hasil analisis kedalam bentuk deskriptif. Kesimpulan hasil observasi menunjukkan bahwa karya kaligrafi mahasiswa Jurusan Pendidikan Guru Madrasah Ibtidaiyah Institut Agama Islam Negeri Ponorogo bertemakan lafadz Asmaul Husna dan Ayat-ayat suci Al-Qur'an memiliki nilai-nilai pendidikan yang terkandung didalamnya. Hal ini bisa dilihat dari pemilihan lafadz, arti lafadz, pemilihan khat, pemilihan warna dan teknik pewarnaan yang digunakan.
\end{abstract}

Kata Kunci: nilai pendidikan, seni, kaligrafi.

\section{Abstract}

In general, each work of art has an exceptional value contained in each of its evaluation ideas. It can be beauty value, educational value, manufacturing techniques and so forth. Islamic calligraphy is one of the missionary endeavour media that has educational value. Therefore, this article would like to review the calligraphy works of students of the Madrasah Ibtidaiyah Teacher Education department State Islamic Institute of Ponorogo in the Arts and Culture Learning at Madrasah Ibtidaiyah course. This study is descriptive qualitative. It is started with reviewing the literature, formulating the theme, creating keywords and formulating analysis results in descriptive forms. The conclusion of observations on the calligraphy works of Madrasah Ibtidaiyah Teacher Education department State Islamic Institute of Ponorogo students with the theme of Asmaul Husna and the holy verses of the Qur'an has educational values contained therein. This can be seen from the word selection, word meaning, line selection, colour selection, and colouring techniques used.

Keywords: educational value, art, calligraphy. 
Nilai-nilai pendidikan dalam seni kaligafi karya mahasiswa jurusan Pendidikan Guru Madrasah Ibtidaiyah

\section{PENDAHULUAN}

Kegiatan seni menulis indah atau kaligrafi telah ada sejak jaman Nabi Muhammad SAW. Kaligrafi sebagai seni islami yang berkaitan dengan tulis menulis memiliki aspek sejarah dalam mengiringi Al-Qur'an. Kaligrafi merupakan visualitas dari ayat-ayat Allah SWT dalam lingkup mikro, sedangkan alam dan isinya merupakan realitas makro ayat-ayat Al-Qur'an ${ }^{1}$. Sirojuddin dalam bukunya Seni Kaligrafi Islam mengemukakan bahwa:

"Khat atau kaligrafi adalah suatu ilmu yang memperkenalkan bentuk huruf-huruf tunggal, letak-letaknya dan cara-cara merangkainya menjadi sebuah tulisan yang tersusun atau apa-apa yang ditulis di atas garis-garis, bagaimana cara menulisnya, dan menentukan mana yang perlu ditulis, mengubah ejaan yang perlu diubah, dan menentukan bagaimana cara mengubahnya" ${ }^{2}$.

Huruf merupakan hasil karya yang diciptakan oleh para pelaku seni, untuk membedakan masing-masing huruf maka diciptakan sebuah penamaan-penamaan khusus yang melatarbelakangi proses penciptaannya, siapa penciptanya, kota asal-muasalnya ataupun dengan peristiwa yang melatar belakanginya. Sebagai contoh tulisan yang dinisbahkan dari tokohnya yakni khat Raihany dari Ali Ibnu Al-Ubaidah Ar-Rayhan, Yakuti dari Yaqut Al-Mu'tasimi, Abbasi dari Shah Abbas, Ismaili dari Ismail Al-Syajari, Gazlani dari Gazlan Bek, Nasiri dari Nasiruddin sampai kepada Syaifuli dari Syaiful Adnan $^{3}$.

Sebagai sebuah seni maka kaligrafi Islam tidak hanya mencakup khat indah namun didalamnya juga memuat pesan-pesan mulia seperti nilai pendidikan. Studi yang dilakukan oleh Roisudin menunjukkan jika pendidikan khat al-'Arabiy dapat membentuk karakter seseorang seperti religius, disiplin, jujur, kerja keras, kreatif, komunikatif, mandiri dan juga dapat membentuk pribadi yang bertanggung jawab ${ }^{4}$. Studi yang dilakukan oleh Ali menunjukkan jika mengenai dakwah juga dapat dilakukan dengan menggunkan Seni Kaligrafi ${ }^{5}$. Sebagaimana yang dilakukan oleh K.H. Moh. Faiz Abdul Razzaq. Sebagai media dakwah maka kali kaligrafi dapat diklasifikasikan menjadi 3 kelompok yaitu upaya pendidikan dan pengajaran, upaya peningkatan kemampuan dan upaya pembentukan

\footnotetext{
${ }^{1}$ Nurul Huda, Zainal Arifin, dan M. Jafar Shodiq, Panduan Belajar Kaligrafi Khat Naskhi dan Khat Riq'ah Untuk Mahasiswa dan Pengajar Bahasa Arab (Yogyakarta: Kaukaba Dipantara, 2014).

${ }^{2}$ Sirajuddinar, Seni Kaligrafi Islam (Jakarta: Pustaka Panjimas, 1985).

${ }^{3}$ Ahmad Zulfkar Ali, "Dakwah k.h. Moh. Faiz abdul Razzaq (Studi Dakwah Melalui Seni Kaligrafi)", Jurnal Reflektka 12, No. 12 (2016).

${ }^{4}$ Ayi Sisma Roisudin, "Menumbuhkan Nilai-Nilai Karakter Melalui Pendidikan Khat Al'Arabiy: Studi Kasus di Sekolah Kaligrafi Al-Qur'an (SAKAL) Pondok Pesantren Mamba'ul Ma' arif Denanyar Jombang”, Journal of Islamic Education 3, No. 1 (2015).

${ }^{5}$ Ahmad Zulfkar Ali, "Dakwah k.h. Moh. Faiz abdul Razzaq (Studi Dakwah Melalui Seni Kaligrafi)", Jurnal Reflektka 12, No. 12 (2016).
} 
komunitas. Hasil serupa juga ditemukan dalam penulisan yang dilakukan oleh Soraya bahwa seni kaligrafi dapat digunakan untuk media dakwah, sebagai media untuk menciptakan kreativitas dan memiliki nilai yang memperkaya budaya bangsa ${ }^{6}$.

Menurut Fauzi Salim Afifi, tujuan pendidikan kaligrafi di sekolah dan tempattempat pembinaan kaligrafi adalah untuk:

1. Mendidik berbagai kemampuan, diantaranya pengawasan, kecermatan memandang, dan kehalusan dalam segala hal.

2. Membentuk rupa-rupa watak dan kebiasaan seperti disiplin, ketertiban, kebersihan, kesabaran dan ketekunan.

3. Memperoleh kemahiran dan keterampilan tangan saat memperbagustulisan dalam latihan.

4. Menumbuhkan kemampuan mengkritik dan menyelami rasa seni setelah mengetahui unsur-unsur keindahan dalam kaligrafi yang bagus.

5. Memperoleh rasa senang dan memperdalam rasa tentram dalam jiwa bila memperoleh kemajuan dalam latihan.

6. Meningkatkan minat dalam jiwa murid untuk menambah kecintaan, perhatian, pemeliharaan, dan karir dalam seni kaligrafi ${ }^{7}$.

Dalam memahami tentang bagaimana bentuk nilai-nilai pendidikan dalam seni kaligrafi karya mahasiswa Jurusan Pendidikan Guru Madrasah Ibtidaiyah, penulis akan mencoba menerapkan teori menurut Kaelani dalam penulisan filsafat, dijelaskan nilai-nilai suatu benda dapat menyangkut tentang objek formal maupun objek material ${ }^{8}$.

objek formal penulisan menurut Kaelan memiliki fungsi sebagai penuntun dalam memecahkan masalah penulisan. Sedangkan objek material penulisan bertujuan sebagai penuntun bagi pemecahan suatu topik penulisan. Topik penulisan ini berjudul nilai-nilai pendidikan dalam seni kaligrafi karya mahasiswa jurusan pendidikan guru madrasah ibtidaiyah maka objek formal penulisan berupa nilai-nilai pendidikan dan objek materialnya adalah seni kaligrafi Islam karya mahasiswa PGMI.

Menurut Maryono, dkk kadar sebuah nilai digolongkan atas nilai ekstrinsik dan intrinsik. Nilai ekstrinsik (contributory value) yaitu sifat baik dari suatu benda dipandang

\footnotetext{
${ }^{6}$ Saskia Soraya, "Nilai dan Makna Kaligrafi Arab pada Masjid Al-Atiq (Analisis Estetik)", Students e-Journals 1, No. 1 (2012).

${ }^{7}$ Fauzi Salim Afifi, Cara Mengajar Kaligrafi Pedoman Guru (Jakarta: Darul Ulum Press, 2002).

${ }^{8}$ Kaelani, Metode Penelitian Kualitatif Bidang Filsafat: Paradigma bagi Pengembngan Penelitian Budaya, Sosial, Semiotika, Sastra, Hukum dan Seni (Yogyakarta: Paradigma, 2005).
} 
Nilai-nilai pendidikan dalam seni kaligafi karya mahasiswa jurusan Pendidikan Guru Madrasah Ibtidaiyah

dari kontribusi benda tersebut pada ruang di sekitarnya atau peranan benda itu sendiri ${ }^{9}$. Nilai intrinsik (consummatory value) yaitu sifat baik dalam diri suatu benda demi kepentingan benda tersebut.

Jakob Sumardjo dalam bukunya yang berjudul Filsafat Seni: Tentang Seni sebagai Nilai merumuskan, seni merupakan sesuatu yang dapat diindera manusia ${ }^{10}$. Setiap seni itu memiliki nilai-nilai dasar yang sama. Nilai dasar dalam hidup manusia, yakni nilai agama, filsafat, seni dan ilmu pengetahuan. Masing-masing nilai tadi mempunyai dasar, aturan, bentuk dan fungsinya sendiri dalam hidup manusia.

Nilai-nilai dasar dalam seni adalah 1) nilai penampilan appearance atau nilai wujud yang melahirkan benda seni. Nilai ini terdiri dari nilai bentuk dan nilai struktur. 2) nilai isi content yang dapat tediri atas nilai pengetahuan kognisi, nilai rasa, intuisi atau bawah sadarmanusia, nilai gagasan dan nilai pesan atau nilai hidup values yang dapat terdiri atas nilai moral, nilai sosial, nilai religi dan nilai pesan lainya. 3) Nilai pengungkapan (presentation) yang menunjukan adanya nilai bakat, nilai ketrampilan dan nilai medium yang dipakainya. Semua dasar-dasar nilai itu menyatu padu dalam wujud seni dan tak terpisahkan. Setiap bahan seni memiliki potensi mediumnya sendiri ${ }^{11}$.

Syaikh Syamsuddin Al-akfani yang dikutip oleh Sirajuddinar menjelaskan seluruh ilmu bisa diketahui hanya apa bila ia mengandung pembuktian (dadalah) baik berupa: isyarat, ucapan ataupun tulisan $(\mathrm{khath})^{12}$. Isyarat mengharuskan adanya kesaksian. Ucapan mengharuskan kehadiran dan kesiapan mendengar dari lawan bicara. Adapun khat, ia tidak tergantung kepada semuanya itu dan karena itulah ia dianggap paling berfungsi diantara ketiga dalalah tersebut.

Penulisan ini berfokus pada karya seni kaligrafi mahasiswa sebagai objek material penulisan. Karya tersebut dibuat oleh mahasiswa Jurusan Pendidikan Guru Madrasah Ibtidaiyah dalam mata kuliah Pembelajaran Seni dan Budaya di MI. Salah satu tugas utama mahasiswa dalam mata kuliah tersebut adalah menciptakan karya seni kaligrafi baik secara individu ataupun berkelompok. Pada tahapan proses penciptaannya, mahasiswa terlebih dahulu diberikan arahan mengenai sejarah, sketsa, teknik pewarnaan, alat dan bahan yang diperlukan. Nantinya semua medium itu dapat menyampaikan isi seni kaligrafi lewat kepiawaian penciptanya.

9 Maryono, Irawan, Suwondo B Sutedjo, Universitas Indonesia, Fakultas Teknik, Pencerminan Nilai Budaya dalam Arsitektur Indonesia: Laporan Seminar Tata Lingkungan Mahasiswa Arsitektur Fakultas Tehnik Universitas Indonesia (Jakarta: Djambatan, 1982).

${ }^{10}$ Jacob, Sumardjo, Filsafat Seni: Tentang Seni sebagai Nilai (Bandung: ITB, 2000).

${ }^{11}$ Jacob, Sumardjo, Filsafat Seni: Tentang Seni sebagai Nilai (Bandung: ITB, 2000).

${ }^{12}$ Sirajuddinar, Seni Kaligrafi Islam (Jakarta: Pustaka Panjimas, 1985). 


\section{METODE}

Studi ini merupakan jenis studi kualitatif yang merupakan penulisan lapangan (field research) sekaligus pustaka (library research). Studi ini berupaya untuk mendeskripsikan secara metodologis, bagaimana proses apresiasi seni dengan cara memaknai sebuah karya seni kaligrafi. Studi ini berusaha untuk mengungkap dan mendiskripsikan objek. Dalam studi ini menggunakan pendekatan fenomenologis yang menekankan pada aspek subjektif, artinya penulis masuk kedunia konseptual dari objek yang ditelitinya, sehingga penulis mengerti tentang apa dan bagaimana pengertian nilai yang dikembangkan. Fenomena kehidupan manusia juga sering dituangkan dalam suatu karya, termasuk seni kaligrafi melalui karya-karya seni kaligrafi fenomena kehidupan manusia dapat dihayati dan dipahami.

Lokasi studi dilakukan di Jurusan Pendidikan Guru Madrasah Ibtidaiyah Institut Agama Islam Negeri Ponorogo. Adapun informan dalam studi ini adalah mahasiswa Jurusan Pendidikan Guru Madrasah Ibtidaiyah Institut Agama Islam Negeri Ponorogo. Adapun langkah-langkah dalam melakukan analisis data dalam studi ini adalah sebagai berikut:

1. Kegiatan utama penulis adalah membaca artikel bertema kaligrafi, pendidikan dan pembelajaran seni. Mencatat informasi dan membaca keterangan data-data yang berhubungan dengan topik penulisan.

2. Kegiatan pada tahap kedua membaca dan mengelompokan kata kunci terutama dalam hubunganya dengan objek formal penulisan dan objek material penulisan.

3. Mengelompokan kategori kaligrafi dalam tema berdasarkan lafadz dan teknik penciptaannya.

4. Mengintegrasikan hasil analisis kedalam bentuk deskripsi, merupakan ringkasan dari data yang dibaca yang memuat unsur-unsur yang persis sama secara logis melalui reduksi data. Reduksi data merupakan memilah-milah yang tidak beraturan menjadi suatu potongan-potongan yang lebih teratur dengan mengoding, menyusun menjadi kategori dan merangkumnya menjadi pola analisis depskriptif dan susunan yang sederhana ${ }^{13}$.

Tahap selanjutnya penulis membuat display data. Display data dibuat secara skematisasi dan interpretasi data. interpretasi merupakan kegiatan pemaknaan dan pemahaman terhadap data dari informan dengan memunculkan konsep dan menjelaskan temuan proses penafsiran dan interprestasi dalam mengungkap makna yang terkandung dalam bahasa tertulis maupun kaligrafi. Model analisis ini akan menjelaskan bagaimana nilai-nilai pendidikan dalam seni kaligrafi Islam karya mahasiswa Jurusan Pendidikan Guru Madrasah Ibtidaiyah (PGMI).

${ }^{13}$ Saryono dan Mekar Dwi Anggraeni, Metodologi Penelitian Kualitatif dalam Ilmu Kesehatan (Yogyakarta: Nuha Media, 2010). 
Nilai-nilai pendidikan dalam seni kaligafi karya mahasiswa jurusan Pendidikan Guru Madrasah Ibtidaiyah

\section{HASIL PENELITIAN DAN PEMBAHASAN}

Penulisan ini dirancang untuk memberikan apresiasi kepada mahasiswa Jurusan Pendidikan Guru Madrasah Ibtidaiyah atas karya kaligrafi yang telah diciptakan guna memenuhi salah satu tugas mata kuliah Pembelajaran Seni dan Budaya di MI. Sejalan dengan pendapat Kartika (2004) menyatakan ada tiga komponen utama dalam seni yaitu seniman, karya seni dan penghayat. Ketiganya saling berinteraksi yang dinamis dan kreatif, maka seni hidup dan berkembang dalam masyarakat.

Dari hasil penulisan dapat disimpulkan bahwa karya kaligrafi mahasiswa jurusan Pendidikan Guru Madrasah Ibtidaiyah (PGMI) memiliki nilai-nilai pendidikan dalam setiap wujudnya. Hal ini bisa dilihat dari pemilihan lafadz, arti lafadz, pemilihan khat, pemilihan warna dan teknik pewarnaan yang digunakan.

Setiap proses penciptaan karya seni pada dasarnya ditopang oleh dua unsur senirupa, yakni fisiko plastis (bentuk karya) dan ideo plastis (isi). Secara fisiko plastis hasil karya kaligrafi selalu memiliki potensi artistik yang tinggi. Selain itu kaligrafi juga banyak mengisyaratkan kemungkinan-kemungkinan (fleksibilitas) yang tidak terduga. Termasuk makna yang tersirat ideo plastis sebagai cita pembahasan bentuk yang dijiwai firmanfirman Allah SWT.

Pada setiap karya-karya seni, isi dan kekuatan pancaranya tidak sama antara satu dan lainnya. Ada karya yang kekuatan pancaranya pada warna, teknik pewarnaan, lafadz, arti lafadz atau berdasarkan khat yang digunakan. Maka dari itu dibawah ini akan dijelaskan secara detail dan terskema hasil karya kaligrafi yang sudah terpilih untuk dijadikan bahan penulisan. Pemilihan karya ditentukan berdasarkan lafadz, teknik dan media yang digunakan. Mengingat tugas kaligrafi mahasiswa terbagi menjadi 2 jenis tema dan media yang berbeda. Tema pertama menggunakan lafadz Asmaul Husna sedangkan tema kedua menggunakan ayat-ayat suci Al-Qur'an. Jika ditinjau dari segi media, karya kaligrafi mahasiswa terdiri dari dua jenis media yang berbeda. Pertama karya dibuat diatas media 2 dimensi (kertas) berukuran a3, kedua karya dibuat diatas media 2 dimensi (kanvas) dengan ukuran yang bervariasi.

\section{Nilai Pendidikan dalam Kaligrafi Basmalah}

Kaligrafi bertuliskan Bismillahirrahmanirrahim dituliskan dengan khat Diwani meski secara penulisan belum seluruhnya benar sesuai dengan tata tulis yang ada. Lafadz kaligrafi merupakan ucapan basmalah yang tertulis secara utuh, Bismillahirrahmanirrahim memiliki makna "Dengan menyebut nama Allah yang Maha Pemurah lagi Maha Penyayang". 


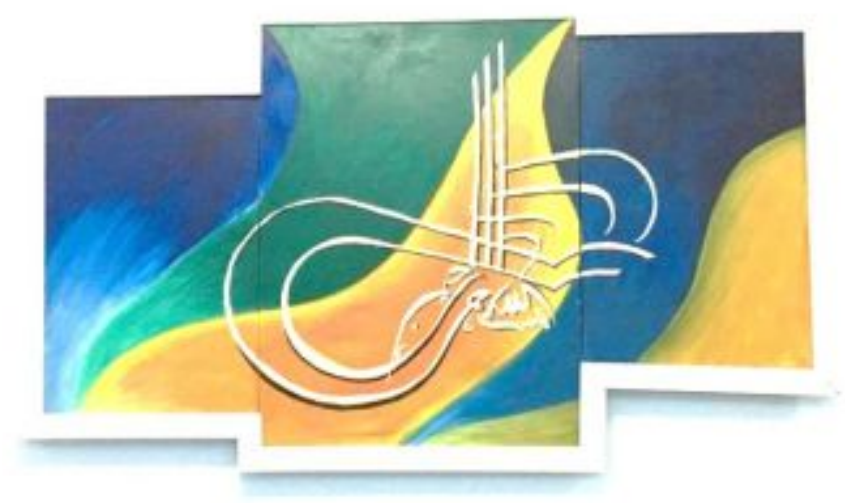

Gambar 1

Warna yang digunakan merupakan perpaduan warna primer dan warna sekunder berupa biru, hijau, dan cokelat. berdasarkan teori warna menurut Sulasmi Darmaprawira W.A (2002:45-49 biru merupakan warna primer yang memiliki arti sejuk, pasif, tenang, dingin, segar. Warna biru melambangkan kedamaian, harapan dan kesucian. Warna biru selalu berhubungkan dengan laut. Hijau melambangkan perenungan, kepercayaan dan keabadian. Warna hijau mempunyai karakter kesegaran, muda, belum dewasa, mentah, kehidupan, pertumbuhan, kesuburan. Warna hijau selalu dihubungkan dengan tumbuhan atau alam. Sedangkan warna cokelat merupakan perpaduan antara warna merah dan hijau yang termasuk dalam kategori warna panas.

Mengacu pada ulasan diatas penulis menyimpulkan secara fisiko plastis kaligrafi dengan lafadz Basmalah menawarkan sisi estetik pada pemilihan khat yang digunakan, khat diwani secara praktik merupakan rangkaian huruf yang saling bersilangan (mutarbit). Selain itu warna yang digunakan merupakan perpaduan warna panas (cokelat) dan warna dingin (biru). Uniknya diantara kedua warna yang saling berseberangan tersebut diselingi warna hijau yang melambangkan perenungan, kepercayaan dan keabadian. Lantas dipertegas dengan pemilihan khat diwani yang saling menyilang mengartikan keterkaitan antara satu dan lainnya. Keunikan tersebut bisa terjadi secara disengaja ataupun tidak disengaja. Sedangkan secara ideo kaligrafi diatas memiliki nilai pendidikan sebagai pengingat bahwa sesungguhnya didunia ini kebaikan dan keburukan selalu berdampingan. Hanya bergantung bagaimana cara kita selaku hamba yang beriman untuk selalu menyebut nama Allah SWT sebagai wujud syukur dan iman dalam melakukan aktifitas sehari-hari. Hal ini diperkuat dengan arti yang terkandung pada lafadz kaligrafi dan pemilihan warna yang mewakili arti kehidupan duniawi. 
Nilai-nilai pendidikan dalam seni kaligafi karya mahasiswa jurusan Pendidikan Guru Madrasah Ibtidaiyah

2. Nilai Pendidikan dalam Kaligrafi surat Ar-Rahman

Pada karya diatas warna kaligrafi didominasi oleh warna biru dengan teknik pewarnaan opaque memberikan kesan warna tebal. Warna biru berdasarkan teori warna menurut Sulasmi Darmaprawira W.A (2002:45-49), merupakan warna primer yang memiliki arti sejuk, pasif, tenang, dingin, segar. Warna biru melambangkan kedamaian, harapan dan kesucian. Secara penulisan, ayat diatas masuk dalam kategori khat tsuluts. Meski secara keseluruhan masih banyak kekurangan secara teknik tata tulisnya. Lafadz kaligrafi sendiri merupakan potongan surat Ar-Rahman dengan ejaan "Fabiayyi alaai robbikumaa tukaddzibaan" yang artinya "maka nikmat tuhan kamu manakah yang kamu dustakan".

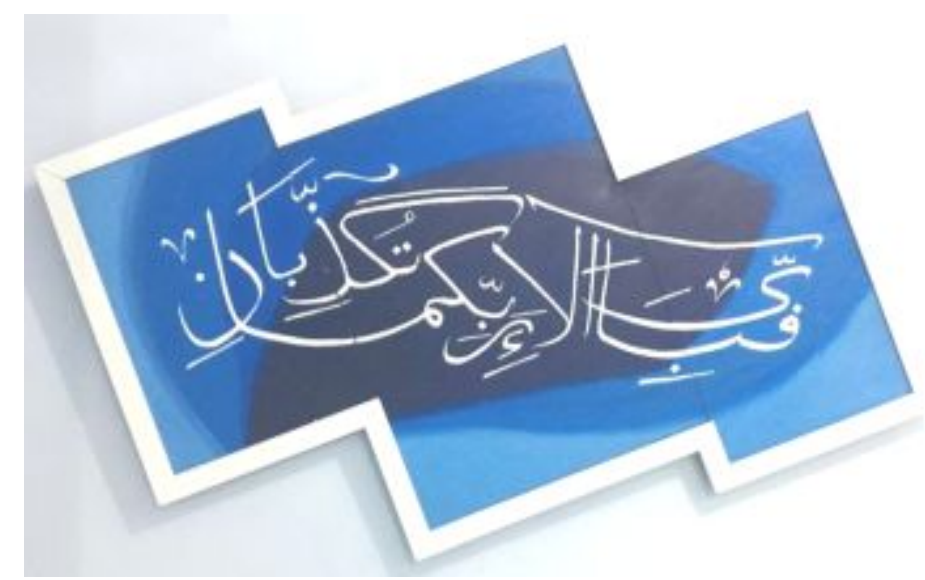

Gambar 2

Berdasarkan ulasan tersebut penulis menyimpulkan kaligrafi diatas secara fisiko plastis menawarkan sisi estetik seni pada suguhan gradasi warna biru. Pemilihan warna biru bisa saja merupakan respon yang diciptakan pencipta karya ketika mengetahui arti lafadz yang dipilihnya. Respon tersebut bisa terjadi secara disengaja ataupun tidak disengaja. Sedangkan secara ideo plastis kaligrafi diatas diharapkan dapat memberikan dampak tenang bagi siapapun yang melihatnya. Hal ini diperkuat dengan arti yang terkandung pada lafadz kaligrafi dan warna yang mewakili arti ketenangan.

Kontribusi kaligrafi diatas untuk pendidikan secara psikologis memberikan seruan kepada penikmat karya untuk selalu bersyukur atas berkah dan kenikmatan yang diberikan oleh semesta. Ketenangan dan nikmat yang didapatkan jangan sampai membuat kita lalai atas karunia-Nya. Dengan begitu penulis berharap karya diatas dapat membuat kita terasadarkan bahwa pendidikan, agama dan iman dapat menghantarkan manusia ke kehidupan yang lebih baik dan sejahtera secara transcendental. 
3. Nilai Pendidikan dalam Kaligrafi Asmaul Husna

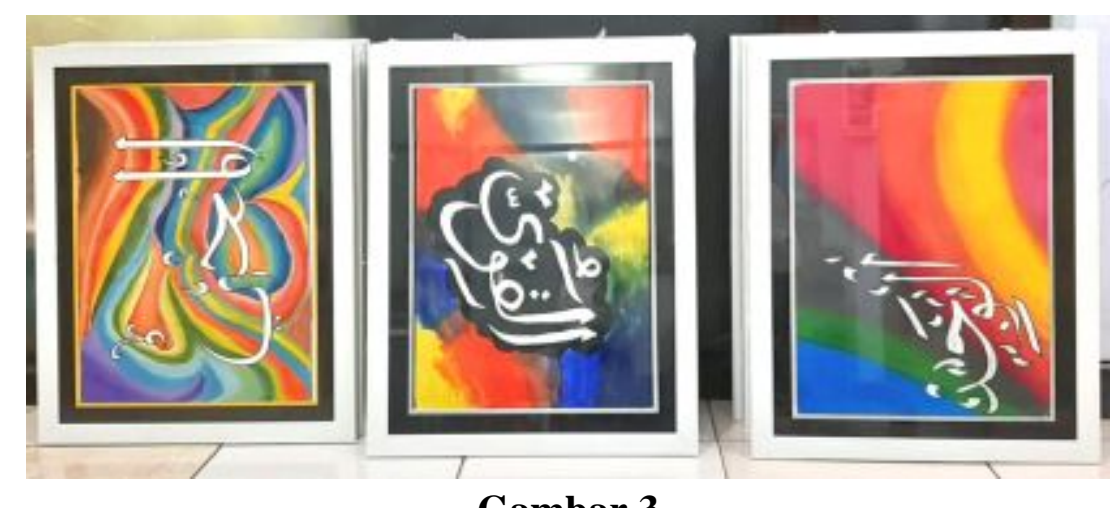

Gambar 3

Kaligrafi bertema Asmaul Husna dengan lafadz Al-Majid, Al-Qowiyyu, Al-Muhyiy bermakna maha mulia, maha kuat dan maha menghidupkan. Kaligrafi diatas dibuat dengan perpaduan teknik pewarnaan basah dan kering, dengan teknik sapuan kuas opaque. Teknik pewarnaan basah digunakan pada bagian background kaligrafi dengan menggunakan cat acrylic. Selanjutnya objek utama menggunakan teknik pewarnaan kering dengan menggoreskan lapisan lilin ataupun crayon putih. Hal ini dilakukan untuk melindungi objek utama dari warna selain warna putih. Sehingga lafadz Asmaul Husna tetap terlihat bersih dan kontras dengan bagian background-nya.

Warna yang digunakan merupakan perpaduan warna primer dan warna sekunder berupa merah, biru, hijau, ungu, orange dan kuning. berdasarkan teori warna menurut Sulasmi Darmaprawira W.A (2002:45-49 Merah adalah warna yang paling kuat dan yang paling menarik perhatian, bersifat agresif dan lambang primitif. Warna merah diasosiasikan sebagai darah, berani, bahaya, seks, gairah, nafsu, dan kekuatan. Biru merupakan warna primer yang memiliki arti sejuk, pasif, tenang, dingin, segar. Warna biru melambangkan kedamaian, harapan dan kesucian. Warna biru selalu berhubungkan dengan laut. Kuning seperti matahari sebagai sumber kehidupan dan juga melambangkan emas sebagai sumber kekayaan. Kuning mempunyai makna lincah, ceria, riang dan senang. Hijau melambangkan perenungan, kepercayaan dan keabadian. Warna hijau mempunyai karakter kesegaran, muda, belum dewasa, mentah, kehidupan, pertumbuhan, kesuburan. Warna hijau selalu dihubungkan dengan tumbuhan atau alam. Warna putih memiliki karakter positif, kejujuran, cemerlang, riang, dan sederhana, serta melambangkan kesucian dan kemurnian. Warna putih diindikasikan kebalikan dari warna hitam. Sedangkan ungu mempunyai karakter khidmad, menyerah dan sejuk. Warna ungu melambangkan dukacita, kesedihan, dan lambang agama. 
Nilai-nilai pendidikan dalam seni kaligafi karya mahasiswa jurusan Pendidikan Guru Madrasah Ibtidaiyah

Kontribusi kaligrafi diatas dalam dunia pendidikan terbagi menjadi dua kategori. Secara fisiko plastis kaligrafi bertemakan Asmaul Husna memiliki teknik pewarnaan modern. Terlihat dari sisi perpaduan teknik pewarnaan basah dan kering yang digunakan. Selanjutnya kaligrafi bertemakan Asmaul Husna memiliki dimensi warna yang bergamam dengan teknik pewarnaan opaque. Sehinga warna-warna pop yang erat kaitannya dengan jiwa muda menjadi gambaran kalangan mahasiswa. Secara ideo palstis kaligrafi diatas memberikan seruan kepada penikmat karya untuk selalu mengingat yang maha kuasa, dengan 3 sifat yang dimiliki-Nya berupa maha mulia, maha kuat dan maha menghidupkan.

\section{KESIMPULAN}

Memaknai sebuah karya seni kaligrafi karya mahasiswa Jurusan Pendidikan Guru Madrasah Ibtidaiyah, merupakan wujud kegiatan apresiasi seni. Apresiasi seni dilakukan agar keberlangsungan kegiatan seni dalam lingkup mahasiswa pada khususnya dan Institut Agama Islam Negeri Ponorogo pada umumnya dapat berkelanjutan. Berdasarkan hasil observasi yang dilakukan, penulis dapat menyimpulkan: 1) Setiap karya seni memiliki makna khusus yang tersimpan dibalik proses penciptaannya, 2) Makna yang terkandung dibedakan menjadi dua jenis, secara fisiko plastis dan ideo plastis, 3) Pemaknaan tersebut terjadi secara sadar ataupun tanpa disadari, 4) Pemaknaan karya seni dan kaitannya dengan pendidikan dilihat berdasarkan lafadz, arti lafadz, pemilihan khat, pemilihan warna dan teknik pewarnaan yang digunakan, 5) karya kaligrafi mahasiswa Jurusan Pendidikan Guru Madrasah Ibtidaiyah memiliki nilai pendidikan dalam setiap proses penciptaannya.

\section{DAFTAR PUSTAKA}

Afifi, Fauzi Salim. 2002. Cara Mengajar Kaligrafi Pedoman Guru. Jakarta: Darul Ulum Press.

Ahmad, Abd Aziz. 1996. Ragam Karakter Kaligrafi Islam. Jakarta: Bumi Aksara.

Ali, Ahmad Zulfkar. 2016. Dakwah k.h. Moh. Faiz abdul Razzaq (Studi Dakwah Melalui Seni Kaligrafi). Jurnal Reflektka, Vol. 12 No. 12. Hal 21-30

Dharsono, Sony Kartika. Seni Rupa Modern. Bandung: Rekayasa Sains, 2004.

Huda, Nurul, Zainal Arifin, dan M. Jafar Shodiq. 2014. Panduan Belajar Kaligrafi Khat Naskhi dan Khat Riq'ah Untuk Mahasiswa dan Pengajar Bahasa Arab. Yogyakarta: Kaukaba Dipantara.

Jacob, Sumardjo. 2000. Filsafat Seni: Tentang Seni sebagai Nilai. Bandung: ITB.

Kaelani. 2005. Metode Penelitian Kualitatif Bidang Filsafat: Paradigma bagi Pengembngan Penelitian Budaya, Sosial, Semiotika, Sastra, Hukum dan Seni. Yogyakarta: Paradigma. 
Tirta D imas W ahyu N, R atna Y unita

Maryono, Irawan, Suwondo B Sutedjo. 1982. Pencerminan Nilai Budaya dalam Arsitektur Indonesia: Laporan Seminar Tata Lingkungan Mahasiswa Arsitektur Fakultas Tehnik Universitas Indonesia. Jakarta: Djambatan.

Roisudin, Ayi Sisma. 2015. Menumbuhkan Nilai-Nilai Karakter Melalui Pendidikan Khat Al-'Arabiy: Studi Kasus di Sekolah Kaligrafi Al-Qur'an (SAKAL) Pondok Pesantren Mamba'ul Ma'arif Denanyar Jombang. Journal of Islamic Education Vol. 3 No. 1.

Saryono dan Mekar Dwi Anggraeni. 2010. Metodologi Penelitian Kualitatif dalam Ilmu Kesehatan. Yogyakarta: Nuha Media.

Sirajuddinar. 1985. Seni Kaligrafi Islam. Jakarta: Pustaka Panjimas.

Soraya, Saskia. 2012. Nilai dan Makna Kaligrafi Arab pada Masjid Al-Atiq (Analisis Estetik). Students e-Journals Vol. 1 No. 1. 